\title{
Exploring Social Markets, Partner Debt, and Mimetic Currency in Dolphins
}

\author{
Christine M. Johnson ${ }^{1, *}$ \\ ${ }^{1}$ Department of Cognitive Science, University of California, San Diego \\ *Corresponding author (Email: c8johnson@ucsd.edu) \\ Citation - Johnson, C. M. (2016). Exploring social markets, partner debt, and mimetic currency in dolphins. Animal \\ Behavior and Cognition, 3(4), 224-242. doi: 10.12966/abc.03.11.2016
}

\begin{abstract}
Dynamic models of "Biological Markets" can provide a systematic and ecologically-valid approach to studying communication and social cognition in dolphins. These market models view interacting animals as traders engaged in a negotiation for social commodities, whose values vary with the state of their current market. Across the phyla, factors like the supply and demand of social resources can impact on investment and partner choice. Such models map well to the polyadic nature of typical social interactions, generating predictions based on configurations of participants, and enabling us to use behavioral observations to address issues of cognitive organization. Plus, by positing communicative signals as social currency, these models provide tools to discern which aspects of dolphins' vocal and gestural repertoires impact on their social relationships. Adapting these models for dolphins highlights the premise that "partnerhood is good," wherein both players gain when they partner. When considered over time, the gains and losses of valued partners may accumulate into "wealth" or "debt" for a particular player, altering its threshold for responding to its market's odds. For example, "Partner Debt" could motivate a player to more readily take action to destabilize its current market. In dolphins, one type of social currency that bears further investigation is the use of vocal and/or gestural mimicry. Such mimesis may promote prosociality, cooperation, and even the coordination of third party information.
\end{abstract}

Keywords - Biological Markets, Dolphins, Social cognition, Communication, Imitation, Mimesis

Dolphins are large-brained, social mammals that live in complex societies which can include collaborative foraging, embedded alliances, fission/fusion, imitation, and elaborate vocal engagement. As such, they are particularly intriguing subjects for research on communication and social cognition. The focus of the workshop on which this special issue is based was the development of new methods and models for such research, adapted to the anatomical, sensory-motor, and social-ecological constraints on these aquatic animals. In this essay, I will review the theory, methods, and results of research on "Biological Markets" (Noë \& Hammerstein, 1995; Noë, van Schaik, \& van Hooff, 1991) and show how this approach can enable us to address critical issues in how dolphins negotiate their social lives. While some aspects of dolphin behavior call for modifications of the model, following its basic tenets provides a systematic program of research that could do much to advance our understanding of dolphin communication and cognition.

This article will begin with a review of the history and key premises of Biological Markets, with examples of market effects in a variety of species. It then turns to adapting these models for use with dolphins, for whom it becomes evident that partnerhood is a valuable commodity. It then will examine the 
effect of differences in partner value and how, accrued over time, "Partner Debt" could impact on an animal's choice to re-partner or opt out, in a given market. Next, it will look at the possible cognitive mechanisms involved, both affective and inferential, and how these might be investigated in socially complex animals like dolphins. It will then discuss the role of time in these accounts, and the methodological options that this engenders. Finally, it will consider the possible use of imitation as social currency in dolphins, and suggest how especially vocal imitation may be studied for its role in market accounts.

\section{Biological Markets}

In "Biological Markets," economic and sociological models of market dynamics have been adapted by biologists to the study of animal behavior (Barrett, Henzi, Weingrill, Lycett, \& Hill, 1999; Gumert, 2007; Henzi \& Barrett, 2002; Kaburu \& Newton-Fisher, 2015; Noë, et al, 1991; Noë \& Hammerstein, 1994; Noë \& Voelkl, 2013; Wei et al., 2016). In a Biological Market, social individuals are seen as members of two "trader classes" who differ in whether they are holding valuable resources, or are willing to "pay" to acquire them. The model assumes that traders will show rational self-interest, making the best deal they can under the circumstances. As a result, buyers compete with others of their class by offering bids of "social currency" (such as grooming in primates) in trade for the holder's commodity. This forms a social market in which supply and demand influence the value of the resources being traded (see Table $1)$.

This work emerged in response to attempts, in theoretical biology, to account for the persistence of cooperation, especially among non-kin, in supposedly self-serving animals, including humans (Axelrod \& Hamilton, 1981; Trivers, 1971). As Axelrod pointed out in his landmark "Evolution of Cooperation" (1984), those who cooperate - i.e., invest in the prospect of gaining a cooperative partner - are subject to exploitation by "cheaters." When an investment has fitness value (e.g., access to mates, food, or other critical resources) taking the offer and paying nothing in return should always give such cheaters an evolutionary edge. Game theoretic models, like the famous Prisoner's Dilemma, were developed to challenge modelers to find tactics that provide greater payoffs to cooperators, demonstrating how cooperation could be established as an "evolutionarily stable strategy." In the iterative form of this game, the two players can track their past interactions, but can never communicate on any trial, and are unaffected by anyone else's transactions. Interestingly, while elegant and highly successful solutions were developed for this game (see Lorberbaum, Bohning, Shastri, \& Sine, 2002), very little empirical data from the field has come to match this model's predictions (for discussion, see Connor, 2010; Noë \& Voelkl, 2013).

As Noë and others (Barrett \& Henzi, 2006; Noë \& Voelkl, 2013) have argued, there are perhaps good reasons why such models, while capturing fundamental aspects of cooperation, still fall short of modeling real-world interactions. The most obvious of these, to anyone who has observed social animals interacting, is that in group-living animals, any dyadic interaction is always immersed in a larger social field. In addition, cooperation is rarely entered into without (sometimes extensive) communication, and payoff values, rather than being fixed, are often among that which is being negotiated. Plus, in the above models, players are, in effect, interchangeable, whereas in the real world, significant asymmetries - in the power to acquire and hold resources, in relatedness or alliance history, even in personality - exist between players that shape how interactions will unfold. Male chimpanzees (Pan troglodytes), for example, were more likely to trade grooming for sex when the power-differential between competing males was small (Kaburu \& Newton-Fisher, 2015). When that differential was large, coercion was more likely to be observed. In fact, it is the well-documented prevalence of asymmetrical power relations in social animals that has shifted biology away from models of two equal players, to ones that include multiple parties and can accommodate differences in negotiation potential (Noë et al., 1991; Noë \& Voelkl, 2013; Port, Clough, \& Kappeler, 2009).

Biological Market models remain concerned with the conditions under which cooperation arises, and retain the presumption of rational self-interest. However, in these models, the focus is less on the 
problems of controlling or besting cheaters, and more on the negotiation - the "bargaining" - that actually accomplishes the cooperative partnership. By treating each interaction as a choice among alternatives,

Table 1

Components of market models, including predictions of tested and proposed studies

\begin{tabular}{|c|c|c|c|c|}
\hline Subjects & Commodity & Currency & Market Effect & Prediction \\
\hline Buyers & $\begin{array}{l}\text { Gain provided } \\
\text { by Seller }\end{array}$ & $\begin{array}{c}\text { Behavior paid by } \\
\text { Buyer }\end{array}$ & $\begin{array}{l}\text { Role of other } \\
\text { participants }\end{array}$ & Supported in studies cited \\
\hline
\end{tabular}

Existing Research

Baboons

Subadult females

Access to infant Grooming

Mate with

female

Tolerance from

dominant males

Gift"

Subordinate males
Present "Nuptial

Submissive Displays

Chimpanzees

Subordinate males

Baboons Troop

mates

\section{Dolphin Proposals}

Dolphins: "Partner

Value" School

mates

Dolphins: "Partner Debt" School mates

Dolphins: "Mimetic Currency" School mates of

mating

Reciprocation

of grooming
Male tolerance Aid in agonism

Partnership, Solicit, Follow, etc.

Collaboration, (vs. Opt Out)

Support, etc.

Partnership, Mimicry of Collaboration, Postures, Calls Support, etc.
\# of infants available in a

given season

\# competitor males on

site

\# non-kin, subordinate males in group

Prolonged conflict leads fighting males to value any available support

"Partner Value" per long-term stability in likelihood of support
Baboons groom a mom for longer if there are fewer infants available (Henzi \& Barrett, 2002)

Female will accept smaller gifts only when fewer males available (Thornhill, 1984)

More spontaneous displays of submission when more subordinates (Kutsukake \& Clutton-Brock, 2008)

Subordinate male gains maximum \# matings by helping/exploiting both players in conflict (de Waal, 1982; Nishida, 1983)

Reciprocity better predicted by long-term history than immediate market (Frank \& Silk, 2009)

Value of partner (per previous likelihood of coop \& odds of competitor gaining partner instead) predicts when Opt Out

PLUS long-term history of relationships

\# competitors/potential

Accrued partner wealth/debt partners PLUS long-term and recent cumulative history of relationships

\# competitors/ potential partners PLUS history of relationships Out

If mimicry has currency value, predict it promotes prosociality, use in effective collaboration, etc. shifts prediction of when Opt

Note. See text for details. 
researchers gain access to the range of influences that community members can bring to bear. As a result, the "coalition games" which, to date, most aptly model such social markets are not dyadic, but require at least three players (Noë et al., 1991; see also Connor 2010). This is because gaining access to a partner of value is seen as a competitive enterprise, in which multiple animals must "outbid" one another in vying for that partner's cooperation. In this scheme, buyers tender some kind of "social currency" - such as grooming in primates, help at the nest in passerine birds, or a "nuptial gift" in scorpion flies - and the seller must choose whose offer to accept for its cooperation. Critically, the value of the seller's "commodity" - its willingness to mate, its support in a fight, its tolerance around a defensible resource, etc. - depends, in part, on supply and demand in this competitive marketplace.

For example, in many primates, an infant is an attractive commodity to other females, who must work to appease the protective mother in order to gain access to her offspring. As Henzi and Barrett (2002) found in chacma baboons (Papio ursinus), the amount of grooming these females must pay, as the cost of the mother's cooperation in handling her infant, is subject to supply and demand. That is, during seasons where there are many infants in the troop, females are required to spend less time grooming a given mother, than they would if there were fewer infants available. Thus when infants are in greater demand, their market value goes up, but then falls as the supply of infants rises (see also Wei et al., 2016).

The currencies and commodities in such markets vary within and across species. In primates, grooming can be exchanged not just for access to infants but also for tolerance at feeding sites, for protection from aggression, for sex, for aid in agonism, or for the calming, trust-building effects of being groomed in return. In avian helpers at the nest, satellite males compete for the opportunity to help feed and defend another pair's offspring, with the potential of inheriting a valuable territory and possibly gaining some extra-pair copulations (Koenig \& Dickinson, 2004). The prey insects offered as "nuptial gifts" by male scorpion flies (Hylobittacus apicalis) are traded for the female's cooperation in mating (Thornhill, 1984). Females accept smaller gifts if only a few males are available, but hold out for larger ones when the supply of male bidders is high. Thus, the value of the currencies being offered, and of the goods and services for which they are traded, vary with the state of these social markets.

While supply and demand play a key role in determining such values, many factors can influence exchange in social markets. By definition, cooperation involves accessing social resources without coercion. Even when commodities can be taken by force, coercion might not always be the most profitable tactic (Noë \& Hammerstein, 1994). It may bring on challenges from contenders, consume energy, pose greater risks (including from predators) if arousal escalates, or impact on players with whom one may want to cooperate in the future. Instead, animals with the power to coerce may need only perform some insignia of their rank to gain those payoffs. Such negotiations tend to be very stereotyped, with ritualized sequences that enact the players' status for one another, and outsiders, to see (see Seyfarth, 1977). In fact, inasmuch as dominant individuals indicate an interest in cooperation, then access to highranking animals can, in and of itself, become a valuable commodity (e.g., Port et al. 2009; Smith, Memenis, \& Holekamp, 2007). Proximity provides the buyers with both an immediate proxy for the resources that the dominant can control, and a means, over time, for a familiarity, that may promote exchange, to grow.

The powers of rank can also be subverted, however, under the right market conditions. In Chimpanzee Politics for example, de Waal (1982) describes a "coup" in which an up-and-coming male usurped the highest ranking male in the troop, in part through gaining the support of lower-ranking allies. Interestingly, during this multi-month negotiation, one ally, whose help was in demand from both the old leader as well as the leader-to-be, managed to parlay his market position into gaining more matings, tolerated perhaps in payment for his help, than any of the high-ranking males (see also Nishida, 1983). Plus, in primates and other coalitional species, lower-ranking animals can form cooperative alliances that can outcompete a dominant individual (see Bissonnette et al., 2015; Harcourt \& de Waal, 1992). In savanna baboons (Papio cynocephalus Anubis), for instance, while an older male may display subordination, in dyadic encounters, to an aggressive new resident, that same older male, in conjunction with a long-term ally, can stand up to and successfully drive off its younger antagonist (Smuts, 1985; Strum, 1987). 
In addition, in individualized societies where animals have repeated opportunities to interact with particular others, their histories of negotiation and cooperation can also alter their market values. For example, many primates show reconciliation - that is, an increase in their tendency to engage in affiliative interactions like grooming, toward an individual with whom they have recently fought. Payment in the form of efforts to reconcile is much more likely between "valuable" partners: ones that have a prolonged history of cooperative interactions (Aureli, Cords \& van Schaik, 2002; Cords, 1997). Additionally, inasmuch as animals can track the value that partners have, not just to them but to others, a web of relations becomes relevant. For instance, in animals who form coalitions, dominant individuals may intervene in the affiliative exchanges of others to disrupt any possible coalition building that could later pose a threat (Chapais, Gauthier, \& Prud'homme, 1995; de Waal, 1982; Nishida \& Hosaka, 1996). This notion of "partner value" will be of particular interest in our attempts to apply the market model to dolphin interactions.

\section{Adapting Market Models for Use with Dolphins}

Dolphins engage in a number of behaviors that suggest that market effects are likely to play a significant role in organizing their social interactions. For example, in many species, collaborative foraging allows animals to access prey more successfully together than one animal can alone (Gazda, Connor, Edgar, \& Cox, 2005; Norris \& Dohl, 1980; Würsig \& Würsig, 1979). In some species, long-term male coalitions compete with other such alliances for access to females (Connor, Heithaus, \& Barre, 1999; Wells, 2003). Reconciliation after aggressive encounters has also been reported (Samuels \& Flaherty, 2000; Weaver 2003; Yamamoto, et al., 2015) and observations of epimeletic (care-giving) behavior - such as support of foundering companions, standing-by when others are captured or injured, active defense of others against predators, etc. - have accumulated on these animals (Connor \& Norris, 1982; Rendell \& Whitehead, 2001). Dolphins' use of animal-specific signature whistles (Caldwell \& Caldwell, 1965; Janik \& Sayigh, 2013) also make clear that theirs is an individualized society. Their capacity to recognize such whistles even after 20 years (Bruck, 2013), as well as to maintain long-term relationships, indicate that they have the experience and memory to track repeated encounters.

While many of the above findings are consistent with conditions that enable market effects to operate, few data have yet been collected to address this possibility. The methods required are not all that different from those commonly used to study dolphin behavior (see Table 2). The main difference would be that the focus must shift from "Who does what to whom?" to "Who does what to whom, while who else is present?" That is, observations can no longer be taken or analyzed dyadically, but must also be assessed relative to the other social options available. In addition, special attention needs to be paid to partner change, to determine under what market conditions different choices are made.

Observing dolphins can also lead to modifications of the market model. Dolphins are a schooling animal. Perhaps because maintaining proximity is such an active process in the ever-moving dolphins, it is particularly apparent that being close to others is a state that dolphins will work to establish and maintain. In the wild, swimming together can provide for group defense against predators, opportunities to collaboratively hunt, and a means of not losing track of one another in the open ocean. While, under certain conditions, partnerhood can be coerced - as when a coalition of bottlenose (Tursiops aduncas) males work to sequester a reproductive female (e.g., Connor, Smolker, \& Richards, 1992) - most often partnerhood requires the cooperation of all participants. In captivity, recent research shows that bottlenose dolphins adjust to tradeoffs between partner value and reinforcement from their trainers (Perelberg \& Schuster, 2009). Given the choice, individual dolphins in this study preferred receiving two-handed, rather than one-handed petting from their trainers. But, even though approaching a trainer as a pair meant that each animal would receive only one-handed petting, the animals most often approached in pairs, indicating that the value of being partnered outweighed that of individual attention from the trainer. Given such observations, we might make the uncontroversial claim that, for these animals, "partnerhood is good." With their large community sizes and common occurrence of fission/fusion (Connor, Wells, Mann, \& Read, 2000; Herzing, 1997; Wells, Irvine, \& Scott, 1980; Würsig \& Würsig, 1977), it may be 
reasonable to expect that a competitive market for swimming partners could exist in dolphins.

Table 2

Some methodological implications of adopting a market model for studies of dolphin communication and social cognition

\begin{tabular}{|c|c|c|}
\hline $\begin{array}{l}\text { Market Model } \\
\text { Features } \\
\end{array}$ & $\begin{array}{l}\text { Research Topics } \\
\text { Addressable } \\
\end{array}$ & $\begin{array}{c}\text { Recommendations for } \\
\text { Data Collection and Analysis }\end{array}$ \\
\hline Value & Motivation & $\begin{array}{l}\text { - Presume rational self-interest, and } \\
\text { - High arousal behavior as costly, and } \\
\text { - Inhibition (suppress provoked response) also costly } \\
\text { - Then ask questions such as . . } \\
\text { - Effort (\# signals, arousal, time) A invests in B, given C? } \\
\text { - Likely to do effortful "repair" when lose partner? } \\
\text { - For valued, longer latencies from solicitation to "opt } \\
\text { out"? }\end{array}$ \\
\hline At least 3 Players & $\begin{array}{l}\text { Supply \& Demand } \\
\text { Competitor Effects } \\
\text { Audience Effects }\end{array}$ & $\begin{array}{l}\text { - Fewer infants, moms demand more for access? } \\
\text { - Females demand more effort when more suitors? } \\
\text { - Males less tolerant of sub-males when their \# increases? } \\
\text { - Probability AB are partners, given if C present/absent? } \\
\text { - How does AB change when C appears/leaves? } \\
\text { - How does AB change, given CD? }\end{array}$ \\
\hline $\begin{array}{l}\text { Signals } \\
\text { as Currency }\end{array}$ & $\begin{array}{l}\text { Signal Repertoire } \\
\text { Imitation } \\
\text { Attention }\end{array}$ & $\begin{array}{l}\text { - Which behaviors, vocalizations, feature in negotiations? } \\
\text { - System stabilizes after what length, type of negotiation? } \\
\text { - Less "repair" required if interrupt at natural boundary? } \\
\text { - Who imitates who in whose presence/absence? } \\
\text { - Consequences of imitation - Prosociality? } \\
\text { Collaboration? } \\
\text { - Imitate signature to solicit? Collaborate? Inform others? } \\
\text { - Learning alters event salience (detection, likely to evoke Rx)? } \\
\text { - Event provokes surprise (bubble, sudden change)? } \\
\text { - Event provokes info-seeking (echolocation, shift view)? }\end{array}$ \\
\hline $\begin{array}{l}\text { Time: } \\
\text { Flow of }\end{array}$ & $\begin{array}{c}\text { Negotiation Types } \\
\text { Adapting to Affordances }\end{array}$ & $\begin{array}{l}\text { - Sequence of behaviors \& calls from identified players } \\
\text { - Track contingencies between calls, behavior, } \\
\text { consequences } \\
\text { - Relative timing (turn taking, synchrony, delayed } \\
\text { mimicry)? } \\
\text { - Patterns assoc'd w/being more/less "demanding" seller? } \\
\text { - Measures of how coordinated } \\
\text { - Efficiency, efficacy of co-achievement? } \\
\text { - Does A's action afford B's action afford A's action, etc? } \\
\text { - Latency to complementary action as "readiness to } \\
\text { respond" } \\
\text { - Ontogenetic ritualization } \\
\text { - Portion of activity jointly refined into signal? }\end{array}$ \\
\hline $\begin{array}{c}\text { Time: } \\
\text { Cumulative }\end{array}$ & $\begin{array}{l}\text { Expertise } \\
\text { Reputation }\end{array}$ & $\begin{array}{l}\text { - Time with/without valued partner accrues "wealth"/"debt" } \\
\text { - Greater debt, lower threshold to "opt out"? } \\
\text { - Repeated partners tighter synchrony? More complementary? } \\
\text { - Repeated collaboration more effective than occasional? } \\
\text { - Smoother execution (less repeat, repair) in experts? } \\
\text { - Difference in valued behavior or target, per audience? } \\
\text { - Difference in surprise, over-reaction, per audience? }\end{array}$ \\
\hline
\end{tabular}


Note. $\mathrm{Rx}=$ Reaction. See text for exposition.

By investigating the choices different animals make on who to join, given their current options, we can observe how partnerhood bargains are struck. Some species preferentially partner with higher ranking others (see Port et al., 2009; Seyfarth 1977; Smith et al., 2007), or with those with whom they have exchanged resources in the past (Gumert, 2007; Perry, Barrett \& Manson, 2004; Silk, 1994). Dolphins, likewise, do not assort indiscriminately. Preferential associations - by kinship, age, reproductive status, and alliance membership - have all been reported in dolphins (e.g., Herzing, 1997; Mann, Connor, Barre, \& Heithaus, 2000; Wells, 2003), although those investigations say little about how such clusters come about. Observing which dolphins initiate such unions, under what market conditions, should provide important data on the dynamics of partner competition. It could also allow us to discover other behaviors and vocalizations that serve as currency in such transactions. (See further discussion, below.)

The presumption "partnerhood is good" has additional implications not yet commonly discussed in the market literature. In typical market-based interactions, in which currency and commodities are exchanged, a sequence of events is generally described. First the buyer offers its payment, and then, if the seller chooses to cooperate, it makes its commodity available. Thus, while over a set of such transactions, an economic balance may be struck, in each component transaction, one animal gains while the other loses. In fact, it is the buyer's risk that its initial payment may not be reciprocated that leads biologists to label such behavior as a "bid" for the desired commodity. But, if "partnerhood is good," when two dolphins both make an effort to come together, then both animals gain. In this scenario, one must ask what becomes of the asymmetry that typically differentiates the two trader classes (buyer and seller) if both profit in a single transaction?

\section{Partner Debt}

Understanding the market dynamics of 'win-win' partnerhood requires recognizing that while both parties gain, they may do so to different degrees. If one partner is more valuable than the other, players will not only gain different values when they come together, but also lose different values when they part. We call the latter "Partner Debt." The animal who has lost the more valuable partner may be more motivated than its previous partner to invest in a reunion, or in an active search for better choices. This heightened motivation may translate into shorter latencies until it invests or defects, more effortful displays to solicit partnerhood, or a shift in the saliency (detectability) of opportunities to partner. And, since the value of any partner depends, in part, on what alternatives are, and have been, available, audience effects would also need to be taken into account.

But, Partner Debt may also entail a cumulative effect. While typical market models use a player's immediate options (based on the competitors and commodities currently available) to predict a buyer's behavior, if its cumulative history of gains over losses is also relevant, rather different results may arise. For example, an animal deeper in long-term Partner Debt could be more impacted by the loss of a partner, even of equal value to itself. That is, faced with the same field of options, the animal in greater Partner Debt may be expected to show a different "tipping point" in its subsequent bargaining. Thus, for example, an animal in less debt may hold out longer, even for a less valuable partner, than one in greater debt, whose options may be more promising elsewhere. Thus, especially for animals like dolphins, who are long-lived and have many repeated encounters, not only should partner value matter, but the wealth/debt that accrues over repeated gains and losses could also be expected to shape the animals' economy.

From a cognitive standpoint, in either debt situation - whether immediate or longer-term - some measure of memory must be assumed. Even in the immediate case, a player's estimate of its last partner's value could be evident in the resetting of its threshold for subsequent choices. The longer-term version would involve players tracking a prolonged course of shifting gain and loss. The extent to which a given species can track such long-term, cumulative effects is, of course, an empirical question. But, to the extent that any learning and memory processes are brought to bear, it seems reasonable to include some form of partnerhood history in the equation. This becomes particularly clear when we recognize how well the 
presumption of rationality, which underlies all market models, maps to a fundamental law of learning theory in psychology, known as the "Law of Effect" (Hernstein, 1970; Thorndike, 1898/1911). This law states that when an animal is in a positively valenced situation (e.g., in the repeated presence of positive reinforcement) it will work to stabilize and maintain that situation (e.g., repeat a conditioned response), and when in a negatively valenced one, will act to destabilize it (e.g., extinguish that response). This law has been shown to apply to learning across the phyla, and provides clear predictions for animals under Partner Debt. For instance, if the loss of a more valuable partner is more negatively valenced than the loss of a less valuable one, then the animal suffering the greater Partner Debt should be more likely to perform an act that is destabilizing to the current state of the market.

A player can alter market dynamics by disrupting the interactions of others or by removing itself as an option. Noë and Hammerstein (1994) argue that the "sampling costs" - the time and effort invested in assessing one's options - are an important part of the equation that determines when an animal should persist in, or opt out of, a given market. If the negative impact of loss is also a factor, then Partner Debt, by incentivizing destabilization, should down-shift the sampling costs a player is willing to incur. Similarly, in a partnership that is more valuable to one partner than it is to the other, the former might be expected to invest more effort in stabilizing both the partnership and the market conditions that support it, and thus tolerate the associated increase in its sampling costs.

\section{Studying Social Cognition}

As noted above, the focus of our workshop was on methods for studying communication and social cognition. While these two topics can be seen as largely synonymous, they do tend to involve different emphases and somewhat different, if overlapping, methodologies. In the context of social markets, communication tends to refer to the types of currency involved - i.e., the signals and actions that constitute the contents of bargaining. Social cognition, on the other hand, focuses more on how the bargaining process is organized - i.e., how those currencies are evaluated and used and what choices are made under what conditions. That is, social cognition is more about the mechanisms responsible for effective, adaptive bargaining.

Some cognitive mechanisms that have been proposed to come into play here are more affective than intellectual. Given that assessments of value are essential in market negotiations, it makes sense that emotional and motivational systems would be involved. In primates, for example, grooming promotes the reduction of cortisol and increases beta-endorphins, producing a calming effect (Keverne, Martensz, \& Tuite, 1989; Spruijt, van Hooff, \& Gispen, 1992). Elaborate trust-building rituals, seen in some primate species, involve potentially risky behavior, such as placing a finger in another's mouth or eye-socket (Perry et al., 2003), or handling another male's testicles (Smuts \& Watanabe, 1990). The recurrent experience of such risk-without-harm is reported most often among valued partners, and fosters the trust that future investment from that partner can be depended upon. What de Waal and colleagues call "attitude mirroring" may also function as an affect-based mechanism (Brosnan \& de Waal, 2002; de Waal, 2000; Suchak \& de Waal, 2012). For example, during co-feeding in Cebus monkeys (Cebus apella), "tolerance breeds tolerance" (Brosnan \& de Waal, 2002), enabling the animals to converge on a stable cooperative state via such attitude matching.

The regulation of anxiety may also be pertinent here. In the research on reconciliation, Aureli and colleagues suggest that social conflict generates anxiety. Actions that reconcile valuable partners reduce uncertainty about the relationship, and thereby relieve that anxiety (Aureli, 1997; Aureli et al., 2002; Cords \& Aureli, 2000). Competition - a cornerstone of market models - can also generate anxiety. When, for instance, the number of non-kin, male meerkats (Suricata suricatta) in a community increases, aggression by the dominant male, after controlling for encounter frequency, also increases (Kutsukake \& Clutton-Brock, 2008). Similarly, the subordinate males involved show an increase in spontaneous (nonprovoked) submissive signals. With so many animals on edge, the risk of attack is heightened. Seeing social negotiation as a way of down-regulating such arousal may provide insights into how communicative signals can operate as social currency, reducing the potential costs of conflict. 
Other more reasoning-based mechanisms that may have evolved to cope with market effects have also been proposed. They include "goal-directed" behavior, "bookkeeping" that tracks the players' history of cooperation, or "inferential processes" about potentially relevant but absent others (for discussion, see Barrett \& Henzi, 2006; Brosnan \& de Waal, 2002; Leavens, Russell, \& Hopkins, 2005). As discussed above, the extent to which such cognition is involved requires a species by species analysis. However, given that market effects are observed in animals as diverse as scorpion flies, cleaner fish (Labroides spp), weaver birds (Euplectes orix), and chimpanzees - and no doubt many different mechanisms can produce similar types of behavior - it can be particularly challenging to identify the specific mechanisms responsible (for discussion, see Barrett, Henzi, \& Rendall, 2007; Strum, Forster, \& Hutchins, 1997). Nonetheless, given the cognitive sophistication that dolphins have shown in other areas (e.g., Herman, 2009; Johnson, 2010; Pack, 2015), we might anticipate that they have developed ways of adapting to complex and changeable environments.

Fortunately, by keeping our focus on the proximate patterns of engagement, we can, in a very real sense, see the cognition involved (Goodwin, 2013; Hutchins, 1995, 2010; Johnson, 2001). Within the market literature, proximate accounts have long focused on moment-by-moment decision making - e.g., how supply and demand influence exchange rates, how information on the value of commodities is obtained and manipulated, how investments and returns affect partner choice, etc. These concerns correspond to those of social cognition, and suggest that to study this topic we might best keep our focus on the particulars of interactions. For example, a fish and a dolphin may both respond to market effects, but if it is true that the dolphin does so in a more complicated way, this should be evident in the variability and flexibility of the bargaining that ensues. That is, by documenting how many different types of currency are involved, how many different types of sequences are produced, how embedded the organization of those sequences is, and how flexibly they are deployed (Byrne, Corp, \& Byrne, 2001; Johnson, 2010, 2015) we may be able to develop metrics for comparing species in terms of the complexity of their negotiations.

Of course, the more complex the animals, the more factors are required to assess and predict social activity. This can place extraordinary demands on researchers and limit what data can feasibly be collected in what settings. Taking systematic observations at sea of partner choice and, inasmuch as underwater behavior can be observed, of the postures, contact, arousal etc. involved in negotiations, can be especially challenging. Even as basic a parameter as rank - typically determined as the outcome of repeated dyadic confrontations, especially involving a priority of access to resources - can be particularly difficult to capture for all possible players in a wild school. New technologies, such as aerial video cameras mounted on drones, can improve what is observed from land-based or boat deck platforms, although critical animal identities must be collected concurrently topside (Nowacek, 2002). Even where animals are acclimated to observers in the water (e.g., Herzing, 2012), tracking known individuals over repeated encounters under different market conditions can be exceedingly difficult.

For studies of the cognitive details, then, it may be more conducive to work with dolphins under human care. Captive settings enable continuous audio and video recording and the advantages of working with a fixed group of animals, where the age, rank, relatedness, and social histories of all participants are known. When these animals are free to sort and re-sort, and to leave or follow one another (e.g., into another pool), such studies can provide rich cognitive data to analyze from a market perspective. Recent developments in technology for recording, reviewing, and analyzing vocalizations and behavior including those described elsewhere in this issue - makes it possible to collect and assess quantities of such data like never before. And the findings of such studies can then impact on the conservation and management of these animals, especially those that will live out their lives in captivity, by helping us to identify what is of value to them, and the conditions required to support such behavior (see White, 2015).

\section{Tracking Market Change Over Time}

One methodological consequence of a focus on the course of particular interactions is that such studies tend to pose temporal questions: What happened when? Before or after what? Under what 
changing conditions? Furthermore, with this focus on change over time, there are multiple time scales to take into account (Hutchins, 1995; Johnson, 2001, 2010). One of the advantages of market models is that they can make predictions about moment-to-moment changes - such as how the addition of a new group member can shift the state of the market enough to alter the value of a choice - as well as about the effects of a long-shared history (see Tables $1 \& 2$ ).

Investigation of fine-scaled, multi-modal engagement is best for discovering which cues the animals are discriminating and manipulating in their negotiations. By observing, for example, what aspects of behavior are salient to the animals - i.e., most likely to become a focus of attention and/or trigger a response, especially involving a change in arousal - we can accumulate critical data on the cognition involved. This time scale can also reveal how bargaining is "parceled" (Connor, 1995, 2010; Kaburu \& Newton-Fisher, 2013). In his discussion of the evolution of reciprocity, Connor (1995) suggested that parceling an exchange into smaller portions of activity could potentially limit cheating, by both reducing the risk of each investment and prolonging the exchange. Noë (2006) describes how, after engaging in a cooperative hunt, a group of lionesses may "parcel" their prey, negotiating the shares that each receives. More generally, the parceling of behavior can make even instrumental acts communicative, as negotiative signals. In "ontogenetic ritualization" (Johnson, 2001, 2010; Tomasello \& Call, 1997; Tomasello, Gust, \& Frost, 1989), for instance, a portion of a social activity is refined, though its repeated use by familiar participants, into a functional signal. In the act of picking up an infant, for example, the two-handed reach that infant primates, including humans, use to solicit that activity is derived from reaching up to grab on during the execution of a carry (Halina, Rossano, \& Tomasello, 2013; Hutchins \& Johnson, 2009). Tracking such developments, over ontogeny or over the course of a negotiation, can help show us how the animals themselves parse their signals (see also Barret \& Henzi, 2006; Johnson, 1993).

Longer-term, historic accounts of social activity can also be useful. They enable us to establish relationship factors like rank, friendship, alliances, etc., that do not tend to rapidly change. They can also enable us to distinguish the effects of expertise. Gazda et al. (2005), for instance, describe the difference in effectiveness in a long-standing group of dolphin cooperators, compared to a less well-established group, in collaborating to herd prey. Long-term accounts can also show us when the animals themselves are tracking their relationships over time. For example, Frank and Silk (2009), in studying grooming in wild olive baboons (Papio anubis), found that the animals did not appear to allocate their efforts based on immediate local conditions, but rather balanced their grooming rates across many bouts, suggesting they were engaged in longer-term contingent relationships.

One consequence of tracking the history of interactions is an improved capacity to distinguish events that are uncommon, such as investment from a novel player. For example, in a study of the relationship between grooming and subsequent food sharing in chimpanzees, de Waal (1997) found that grooming, between animals who rarely groomed, more strongly predicted subsequent sharing than grooming between common partners did (see also Brosnan \& de Waal, 2002). This may be because anomalous events are salient, standing out against statistical regularity. Or it may be that common partners tolerate greater fluctuations, and thus are less responsive to short-term shifts in payment. In either case, for the researchers, it is only by tracking the history of social interactions that we can recognize such atypical events. Such events often provide distinctive reactions - like surprise, and further informationseeking behavior - that are easily detected and can be highly telling in assessments of socio-cognitive dynamics.

The social implications of unexpected events can ramify through a marketplace. Cheney, Seyfarth, and Silk (1995) saw this in playback experiments with wild chacma baboons (Papio cynocephalus ursinus), in which they first recorded the stereotyped dominance and submission calls made in interactions between animals of different ranks. During the playback phase, from a hidden speaker, they either replayed those pairs of calls, or played anomalous, fabricated pairs. In the anomalous pairs, the voice of the dominant animal is heard making a subordinate call (which it had made in a recorded interaction with a higher-ranking animal) and the subordinate was heard to give the dominance call (recorded from its interaction with a lower-ranking animal). The subjects in that community who heard the normal pairings responded very little. But when they heard the anomalous pairings, they searched the 
surrounding area, seeking additional information about this apparent violation of their expectations regarding the vocalizers' relationship. It is just such an interest in the relationships of others, in addition to one's own relationships, that distinguish socially "complex" animals (Cheney \& Seyfarth, 2007; de Waal, 1986; Johnson, 2010), and will be important to track in dolphins.

Examples of animals observing and interpreting the bargaining of others could also provide data on the role of reputation, or "image scoring," in a social market (Bshary \& Noe, 2003; Nowak \& Sigmund, 1998; Zahavi, 1995). Such assessments can apparently occur over a wide range of time scales. For example, reputation operates on a relatively short time scale in mantis shrimp (Caldwell, 1986), who typically ward off competition from their home cavities in the coral reef by waving their large pincer claw. These shrimp molt these claws periodically and, interestingly, the vigor and duration of claw waving increases dramatically just before the molt. This "bluff" apparently serves to prevent confrontation over the hole, at least from the neighbors that observed the display, for a few days, long enough for the shrimp to grow a new claw. Of course, reputation of the sort described for primates, or other long-lived, long-memoried animals like dolphins (Bruck, 2013), may well be based on much longer time scales, requiring much more extensive data collection and analyses.

Another temporal relation that has proved useful in studying cognitive activity in humans concerns how subjects deal with disruptions (Miyata \& Norman, 1986; Speier, Vessey, \& Valacich, 2003; Zacks \& Tversky, 2001). When a subject is engaged in an ongoing sequence of behavior, the impact of an interruption depends on the organization of that sequence. That is, if the interruption is at a "natural" boundary between sub-tasks, it will tend to be less disruptive - require less back-tracking, promote fewer errors, etc. - than if it occurs in the middle of such a subtask (see Goodwin, 1980). This could be particularly useful in studying dolphin communication, where so little is yet known about how such interactions are organized. For example, when multiple animals are interacting, careful observations of the impact of disruptions may help us distinguish when a series of gestures and calls constitutes a single coherent exchange versus distinct phases, or subtasks, within a negotiation.

The issue of disruption also arises in the reconciliation literature, in which the escalation of aggression is seen as disruptive to the participants' relationship. That relationship is actively "repaired," then, by acts of reconciliation (Cords, 1997). Since this is more likely when more valuable partners are involved (Aureli et al., 2002; Cords \& Thurnheer, 1993), the cognitive implications include both the assignment of partner value, and the motivation to make efforts to re-stabilize the more favorable market state. Similarly, an animal deeper in Partner Debt might be expected to react more strongly to disruptions of its valuable partnerships, especially at a critical junction in their negotiation.

Another sort of disruption is brought about by fission/fusion, where subgroup membership in a community frequently changes (Aureli et al., 2008). By continually altering the options available in the current market, fission/fusion may exert selective pressure for animals to be flexible in adapting to local conditions, as well as to retain memory for the residual state of relationships that have not been negotiated for some time (Barrett \& Henzi, 2006; Johnson, 2010). In dolphins, memory demands, during fission/fusion, for absent but still relevant others, may have also played a role in the emergence of signature whistles, as well as the imitation of the signatures of absent others (see further discussion, see below).

\section{Mimetic Currency in Dolphins?}

Adapting market models for dolphins also suggests another type of currency that may be relevant, one that has as yet received little attention in the market literature - mimesis (Donald, 1993; Zlatev, 2007). Mimesis is the use of imitation in a communicative context. While imitation can serve many functions learning skills from others, drawing attention to aspects of the environment, blending in with the group, etc. - it is as a social signal that it may best serve as market currency.

Humans have long been known to imitate one another in social situations (see Garrels, 2011; Hurley \& Chater, 2005). If, as the aphorism suggests, imitation is the highest form of flattery, then it is no surprise that research shows that imitation promotes prosociality in humans. A subject who has been 
recently imitated is more likely to be helpful or generous, even toward an uninvolved third party (Carpenter, Uebel, \& Tomasello, 2013; Lakin \& Chartrand, 2003; van Baaren, Holland, Kawakami, \& van Knippenberg, 2004). Cebus monkeys are also more likely to engage with those of their human keepers who have recently imitated them (Paukner, Suomi, Visalberghi, \& Ferrari, 2009). While mounting evidence suggests that multiple species of primates recognize when they are being imitated (Haun \& Call, 2008; Nielsen, Collier-Baker, Davis, \& Suddendorf, 2005; Paukner, Anderson, Borelli, Visalberghi, \& Ferrari, 2005), market researchers have yet to investigate whether this behavior can function as social currency in these animals.

The work of de Waal and colleagues on "attitude mirroring" in Cebus (Brosnan \& de Waal, 2002) may also fit under the rubric of mimesis. These monkeys tend to mimic one another's tolerance of dropped-food scrounging, when it is their turn to control food resources. It may be that the act of matching tolerance level, or other prosocial attitude, is a reliable currency for enabling market activity to settle into a stable, mutually-beneficial state. In fact, in general, prosociality often involves a sameness of behavior, such as co-engagement in feeding, travel, or rest. To what extent the animals can bid and barter with such currency remains to be investigated.

Dolphins are prime candidates for making use of mimetic currency, given that they display behavior-matching in a wide variety of contexts. From birth, infants synchronize their behavior with their mothers (Fellner, Bauer, \& Harley, 2006). Staying close and matching her moves results in hydrodynamic "slipstreaming" which both reduces the infant's energetic costs and positions it to listen in on the echoes from her sonar (see also Xitco \& Roitblat, 1996). Later in life, as cooperative hunters working under water, dolphins' collaborative attacks often require synchronized behavior. This occurs, for example, when a pod of Orcas aligns abreast to create a wave that washes an Antarctic seal off an ice flow (Smith, Siniff, Reichle, \& Stone., 1981; Visser et al., 2007), or when a team of bottlenose drive a school of prey fish up onto a beach (Gisburne \& Connor, 2015; Petricig, 1995).

Dolphin coalitions provide the best evidence to date for synchrony as a signal of social value (Connor, Smolker, \& Bejder, 2006; Herzing, 2015). Male bottlenose coalitions, for example, put on elaborate synchronous displays, involving rapid, erratic or periodic movements, duplicated with millisecond fidelity. Similarly, coalitions of spotted dolphins (Stenella frontalis) will synchronize an intensive iteration of aggressive squawks, aligning their heads such that, with their highly-directional sonic beams, they acoustically co-target their antagonists (Herzing, 2015). Experienced coalitions coordinate both their squawks and their orientation much more precisely than their less experienced counterparts. This difference in expertise suggests that the dolphins' skill at synchronization continues to improve over their lifetime which, in turn, suggests that it is of increasing value to them.

However, the common use of synchrony, in and of itself, does not assure that a species can also use delayed imitation to communicate. Other data, however, suggest that dolphins may have such skills (see Tayler \& Saayman, 1973; Kuczaj \& Yeater, 2006). In the lab, they have been trained to produce such imitation, generating copies of previously observed actions, performed either by their own species or by human models (Bauer \& Johnson, 1994; Herman, 2002; Jaakkola, Guarino, \& Rodriguez, 2010). The latter requires the cognitive capacity to map our dissimilar bodies - arms and hands to pectoral fins, legs and feet to peduncle and flukes, etc. - reflecting the level of flexibility required of true mimesis. That they make use of this ability in social circumstances was supported by the observation of a captive spinner dolphin who had suffered an injury that led to its swimming in a wobbling fashion (Johnson \& Norris, 1994). This animal would often rest at the surface of its shared pool, and was occasionally approached by others in the group. His common partners would wobble during their approach to him, matching his stereotyped patterns of movement, and this mimetic device often evoked his partnering with them.

While our understanding of dolphin vocal communication is still in its infancy, it may be that this domain will have the most to offer on imitation as social currency. Cetaceans are remarkable, among mammals, for their capacity for vocal mimicry (Richards, Woltz \& Herman, 1984; Ridgway, Carder, Jefferies \& Todd, 2012; Murayama, Iijima, Katsumata, \& Arai, 2014). While common in many bird species, vocal mimicry is not typically described in mammals, outside of humans and cetaceans (although see Knörnschild, Nagy, Metz, Mayer, \& von Helversen, 2010; Poole, Tyack, Stoeger-Horwath, \& 
Watwood, 2005; Ralls, Fiorelli, \& Gish, 1985). In birds, imitation is a common mechanism of song development (see Boughman \& Moss, 2003; Marler, 1997). Local dialects in white crown sparrows, for example, situate each mimic as a familiar neighbor, not requiring the investment of the competitive displays that one would show to a stranger. The sheer accumulation of calls in a mockingbird's varied mimetic repertoire is apparently attractive to females. Similarly, the humpback whale's accomplishment of remembering a long, multi-phrase song, and keeping up with local changes to it over the course of a breeding/mating season (Darling, Jones, \& Nicklin, 2006; Payne \& Payne, 1985) may serve as mimetic currency in its mating market. But it is the further suggestion, in dolphins, of a more nuanced, occasional, and strategic use of vocal imitation that holds the best promise of revealing the complex course of dolphin bargaining.

As mentioned above, dolphins produce "signature whistles," stereotyped contours made the great majority of time by one individual and occasionally by others in its group (Caldwell \& Caldwell, 1965; Harley, 2008; Janik \& Sayigh, 2013). It is generally assumed that signature whistles function to identify individuals in dark and murky waters, and are known to be produced by individuals who are temporarily isolated from their group, as during brief capture-and-release procedures for data collection on wild animals (Sayigh, Esch, Wells, \& Janik, 2007). The functions of using another animal's signature are much less clear. What little data gathered so far on this indicate that such mimicry occasionally occurs in answer to that same call by the signatore (Janik, 2000; King, Sayigh, Wells, Fellner, \& Janik, 2013), but our preliminary research indicates that such calls are used in a wide variety of social contexts (Johnson et al., 2015; see also Harley, 2008; Tyack, 1986).

Might signatures be imitated by others as a way to solicit partnership, to voice support, or to otherwise promote some prosocial attitude? As such, would it then function as social currency, subject to market effects? And what of the many other, non-stereotyped whistles and other call types made by dolphins? Are they also imitated? Might imitated calls, especially signatures, be modified in ways that connote some attitude - solidarity, supplication, derision, etc. (see Connor, 2007)? And what of the times when the signature of an absent animal is used by a second to a third (e.g. Watwood, 2003)? We identified over 100 such calls, in $20 \mathrm{hrs}$ of recording seven animals, in a four-tank system that allowed for fission/fusion (Johnson et al., 2015). Could such imitation be a commodity of value for conveying information about absent others? Such questions must remain speculative until we can collect the appropriate data on the calls made by all members of a group as they form and change partners.

Work on dolphin vocal communication has long been stymied by difficulties in identifying, underwater, which animals are making which calls. Multiple-hydrophone arrays can help (Starkhammar, et al., 2012; Thomas, Fristrup, \& Tyack, 2002), but these are not yet capable of resolving which of two, proximal, freely-moving animals within a school of many are calling (although see exciting new developments in Hoffmann-Kuhnt et al., this issue). An alternative solution is to use "data-tags" - devices that are temporarily attached, with suction cups, to individual animals, to record their vocal activity (Johnson \& Tyack, 2003). To date, these tags have only been used on one or a few animals at a time, to record all the calls that occur in a given animal's group. To collect the data required to assess whether vocal imitation serves as market currency, all the animals in a given group would need to be tagged and recorded. With simultaneous video recording of the animals' behavior, we would then be in a position to determine whether mimesis is indeed used by the animals in their market negotiations.

\section{Conclusion}

In summary, market models have much to offer for furthering our understanding of dolphin communication and social cognition. By presuming rational players of differential value, these models provide a motivational structure that can be predictive of individual behavior in a given marketplace. By insisting on no fewer than three players, such models enable us to chart the effects of system-level constraints, like supply and demand, and offer a more ecologically valid view of multi-party negotiations. They also provide a dynamic account of transitions between market states, as players cooperate, change partners, or opt out, that generate novel predictions with each change in configuration of participants. By 
seeing communicative signals as currency in a social negotiation, they provide tools to discern which aspects of our animals' vocal and gestural repertoires impact on their social relationships. And with their emphasis on the immediate environment, and provisions to track changes in social configuration on a moment-to-moment basis, they give us a way of using observations of naturally-occurring behavior to learn something of the cognitive organization these animals bring to the task. Not only can we observe how currencies are used and exchanged, but also how temporal factors like reputation, disruption, or novelty are recognized and responded to. All of the above are particularly advantageous when the subjects of interest live in multi-tiered, fission/fusion societies that show polyadic cooperation, long term associations, and high rates of partner change.

Applying market concepts to dolphins highlights their wide applicability and suggests modifications that expand the existing models. For example, if we presume, as seems natural for dolphins, that "partnerhood is good" - such that both players always profit from it - we shift away from the typical dynamic of "holding" vs. "non-holding" players. Further, extending the importance of time in these models suggests that the animals' shared history, both over the long-term, as well as over the course of a given interaction, can result in factors like "Partner Debt" that may alter the cost/benefit analyses that predict partner choice. In particular, the negative valence of partner debt should motivate a player to more readily destabilize its current market, by shifting its threshold for response to that market's odds. Finally, in considering the possible currencies in this system, the prevalence of synchrony and imitation in reports of dolphin behavior suggest that vocal and/or gestural mimicry may play a significant role in their market negotiations. Deploying such models prepares us to investigate these and related issues in a way that is both consistent with the tenets of evolutionary biology and can provide insights specific to the complexities of dolphin social cognition.

\section{Acknowledgements}

The author would like to thank Mallory Kraus, Sunia Suhail, Deborah Forster and Ed Hutchins for insightful discussion and critiques of this paper, and to the reviewers of this paper for their many helpful suggestions.

\section{References}

Aureli, F., Cords, M., \& van Schaik, C. P. (2002). Conflict resolution following aggression in gregarious animals: A predictive framework. Animal Behaviour, 63, 1-19.

Aureli, F., Schaffner, C. M., Boesch, C., Bearder, S. K., Call, J., Chapman, C. A., ... \& Holekamp, K. (2008). Fission/fusion dynamics: New research frameworks. Current Anthropology, 49, 627-654.

Axelrod, R. (1984). The evolution of cooperation. New York, NY: Basic Books.

Axelrod, R., \& Hamilton, W. D. (1981). The evolution of cooperation. Science, 242, 1390-1396.

Barrett, L., \& Henzi, P. (2006). Monkeys, markets and minds: Biological markets and primate sociality. In P. M. Kappeler \& C. P. van Schaik (Eds.), Cooperation in primates and humans (pp. 209-232). Berlin, Germany: Springer.

Barrett, L., Henzi, P., \& Rendall, D. (2007). Social brains, simple minds: does social complexity really require cognitive complexity? Philosophical Transactions of the Royal Society of London, B, 362, 561-575.

Barrett, L., Henzi, S. P., Weingrill, T., Lycett, J. E., \& Hill, R. A. (1999). Market forces predict rooming reciprocity in female baboons. Proceedings of the Royal Society, London B, 266, 665-670.

Bauer, G., \& Johnson, C. M. (1994). Trained motor imitation by bottlenose dolphins (Tursiops truncatus). Perceptual and Motor Skills, 79, 1307-1315.

Bissonnette, A., Perry, S., Barrett, L., Mitani, J. C., Finn, M., Gavrilets, S., \& de Waal, F. B. M. (2015). Coalitions in theory and reality: A review of pertinent variables and processes. Behaviour, 152, 1-56.

Boughman, J. W., \& Moss, C. F. (2003). Social sounds: Vocal learning and development of mammal and bird sounds. In A. Simmons, A. N. Popper, \& R. R. Fay (Eds.), Acoustic communication. Springer handbook of auditory research, Vol. 16. (pp. 138-224). New York: Springer.

Brosnan, S. F., \& de Waal, F. B. M. (2002). A proximate perspective on reciprocal altruism. Human Nature, 13, $129-152$. 
Bruck, J. N. (2013). Decades-long social memory in bottlenose dolphins. Proceedings of the Royal Society B, 280, 20131726.

Bshary, R., \& Noe, R. (2003). Biological markets: The ubiquitous influence of partner choice on the dynamics of cleaner fish-client reef fish interactions. Genetic and Cultural Evolution of Cooperation, 9, 167-184.

Byrne, R. W., Corp, N., \& Byrne, J. M. E. (2001). Estimating the complexity of animal behavior: How mountain gorillas eat thistles. Behaviour, 138, 525-557.

Caldwell, R. L. (1986). The deceptive use of reputation by stomatopods. In R.W. Mitchell \& N. S. Thompson (Eds.) Deception: Perspectives on human and nonhuman deceit (pp. 129-146). Albany, NY: SUNY Press.

Caldwell, M. C., \& Caldwell D. K. (1965). Individualized whistle contours in bottlenose dolphins (Tursiops truncatus). Nature, 207, 434-435.

Carpenter, M., Uebel, J., \& Tomasello, M. (2013). Being mimicked increase prosocial behavior in 18-month old infants. Child Development, 84, 1511-1518.

Chapais, B., Gauthier, C., \& Prud'homme, J. (1995). Dominance competition through affiliation and support in Japanese macaques: An experimental study. International Journal of Primatology, 16, 521-536.

Cheney, D. L., \& Seyfarth, R. M. (2007). Baboon metaphysics: The evolution of a social mind. Chicago: University of Chicago Press.

Cheney, D. L., Seyfarth, R. M., \& Silk, J. B. (1995). The response of female baboons (Papio synocephalus ursinus) to anomalous social interactions: Evidence for causal reasoning? Journal of Comparative Psychology, 109, $134-141$.

Connor, R. C. (1995). Impala allogrooming: Tit-for-tat or parceling? Animal Behaviour, 49, 528-530.

Connor, R. C. (2007). Complex alliance relationships in bottlenose dolphins and a consideration of selective environments for extreme brain size evolution in mammals. Philosophical Transactions of the Royal Society $B, 362,587-602$.

Connor, R. C. (2010). Cooperation beyond the dyad: On simple models and a complex society. Philosophical Transactions of the Royal Society B, 365, 2687-2697.

Connor, R. C., Heithaus, R. M., \& Barre, L. M. (1999). Super-alliance of bottlenose dolphins. Nature, 371, 571572.

Connor, R. C., \& Norris, K. S. (1982). Are dolphins reciprocal altruists? American Naturalist, 119, 358-374.

Connor, R. C., Smolker, R., \& Bejder, L. (2006). Synchrony, social behaviour and alliance affiliation in Indian Ocean bottlenose dolphins, Tursiops aduncus. Animal Behaviour, 72, 1371-1378.

Connor, R. C., Wells, R., Mann, J., \& Read, A. (2000). The bottlenose dolphin: Social relationships in a fissionfusion society. In J. Mann, R. Connor, P. Tyack, \& H. Whitehead (Eds.), Cetacean societies: Field studies of whales and dolphins (pp. 91-126). Chicago: University of Chicago Press.

Connor, R. C., Smolker, R. A., \& Richards, A. F. (1992). Two levels of alliance formation among male bottlenose dolphins (Tursiops sp.). Proceedings of the National Academy of Sciences USA, 89, 987-990.

Cords, M. (1997). Friendships, alliances, reciprocity and repair. In A. Whiten \& R. W. Byrne (Eds.), Machiavellian intelligence II (pp. 24-49). Cambridge, U.K.: Cambridge University Press.

Cords, M., \& Thurnheer, S. (1993). Reconciliation with valuable partners by long-tailed macaques. Ethology, 93, $315-325$.

Darling, J. D., Jones, M. E., \& Nicklin, C. P. (2006). Humpback whale songs: Do they organize males during the breeding season? Behaviour, 143, 1051-1101.

de Waal, F. (1982). Chimpanzee politics. New York: Harper \& Row.

de Waal, F. B. M. (1986). Dynamics of social relationships. In B. B. Smuts, D. L. Cheney, R. M. Seyfarth, R. W. Wrangham, \& T. T. Struhsaker (Eds.), Primate societies (pp: 421-430). Chicago: University of Chicago Press.

de Waal, F. B. M. (2000). Attitudinal reciprocity in food sharing among brown capuchin monkeys. Animal Behaviour, 60, 253-261.

Donald, M. (1993). Precis of "Origins of the modern mind: Three stages in the evolution of culture and cognition." Behavioral and Brain Sciences, 16, 737-791.

Fellner, W., Bauer, G. B., \& Harley, H. E. (2006). Cognitive implications of synchrony in dolphins: A review. Aquatic Mammals, 32, 511-516.

Frank, R. E., \& Silk, J. B. (2009). Impatient traders or contingent reciprocators? Evidence for extended time-course of grooming exchanges in baboons. Behaviour, 146, 1123-1135.

Garrels, S. R. (2011). Mimesis and science. East Lansing, MI: Michigan State University Press. 
Gazda, S. K., Connor, R. C., Edgar, R. K., \& Cox, F. (2005). Division of labor with role specialization in group hunting bottlenose dolphins (Tursiops truncatus) off Cedar key Florida. Proceedings of the Royal Society of London B, 227, 135-140.

Gisburne, T. J., \& Connor, R. C. (2015). Group size and feeding success in strand-feeding bottlenose dolphins (Tursiops truncatus) in Bull Creek, South Carolina. Marine Mammal Science, 31, 1252-1257.

Goodwin, C. (1980). Restarts, pauses and the achievement of a state of mutual gaze at turn-beginning. Sociological Inquiry, 60, 272-302.

Goodwin, C. (2013). The co-operative, transformative organization of human action and knowledge. Journal of Pragmatics, 46, 8-23.

Gumert, M. D. (2007). Payment for sex in a macaque mating market. Animal Behaviour, 74, 1655-1667.

Halina, M., Rossano, F., \& Tomasello, M. (2013). The ontogenetic ritualization of bonobo gestures. Animal Cognition, 16, 653-666.

Harcourt, A., \& de Waal, F. B. M. (1992). Coalitions and alliances in humans and other animals. New York: Oxford University Press.

Harley, H. E. (2008). Whistle discrimination and categorization by the Atlantic bottlenose dolphin (Tursiops truncatus): A review of the signature whistle framework and a perceptual test. Behavioural Processes, 772, 243-268.

Haun, D. B. M., \& Call, J. (2008). Imitation recognition in great apes. Current Biology, 18, R288-R290.

Henzi, S. P., \& Barrett, L. (2002). Infants as a commodity in a baboon market. Animal Behaviour, 63, 915-921.

Henzi, S.P., Barrett, L., Gaynor, D., Greeff, J., Weingrill, T., \& Hills, R. A. (2003). Effect of resource competition on the long-term allocation of grooming by female baboons: Evaluating Seyfarth's model. Animal Behaviour, $66,931-938$.

Herman, L. M. (2002). Vocal, social, and self-imitation by bottlenosed dolphins. In C. Nehaniv \& K. Dautenhahn (Eds.), Imitation in animals and artifacts (pp. 63-108). Cambridge, MA. MIT Press.

Herman, L. M. (2009). Language learning and cognitive skills. In W. F. Perrin, B. Würsig, \& J. G. M. Thewissen (Eds.), Encyclopedia of marine mammals, 2nd Edition (pp. 665-672). New York: Academic Press.

Hernstein, R. J. (1970). On the law of effect. Journal of Experimental Analysis of Behavior, 13, 243-266.

Herzing, D. L. (1997). The life history of free-ranging Atlantic spotted dolphins (Stenella frontalis): Age classes, color phases, and female reproduction. Marine Mammal Science, 13, 576-595.

Herzing, D. L. (2006). The currency of cognition: Assessing tools, techniques, and media for complex behavioral analysis. Aquatic Mammals, 32, 544-553.

Herzing, D. (2012). Dolphin diaries: My 25 years with spotted dolphins in the Bahamas. New York: St. Martin's Press.

Herzing, D. L. (2015). Synchronous and rhythmic vocalizations and correlated underwater behavior of free-ranging Atlantic spotted dolphins (Stenella frontalis) and bottlenose dolphins (Tursiops truncatus) in the Bahamas. Animal Behavior and Cognition, 2, 14-29.

Hurley, S., \& Chater, N. (2005). Perspectives on human imitation (Vols 1 \& 2). Cambridge, MA: MIT Press.

Hutchins, E. (1995). Cognition in the wild. Cambridge, MA: MIT Press.

Hutchins, E. (2010). Cognitive ecology. Topics in Cognitive Science, 2, 705-715.

Hutchins, E., \& Johnson, C. M. (2009). Modeling the emergence of language as an embodied collective cognitive activity. Topics in Cognitive Science, 1, 523-546.

Jaakkola, K., Guarino, E., \& Rodriguez, M. (2010). Blindfolded imitation in a bottlenose dolphin (Tursiops truncatus). International Journal of Comparative Psychology, 23: 671-688.

Janik, V. M. (2000). Whistle matching in wild bottlenose dolphins (Tursiops truncatus). Science, 289, 1357-1360.

Janik, V. M., \& Sayigh, L. S. (2013). Communication in bottlenose dolphins: 50 years of signature whistle research. Journal of Comparative Physiology A, 199, 479-489.

Johnson, C. M. (1993). Animal communication via coordinated cognitive systems. In P. P. G. Bateson, N. Thompson, \& P. Klopfer, (Eds.), Perspectives in ethology, Volume X: variability in behavior (pp. 187-207). New York: Plenum.

Johnson, C. M. (2001). Distributed primate cognition. Animal Cognition, 4, 167-183.

Johnson, C. M. (2010). Observing cognitive complexity in primates and cetaceans. International Journal of Comparative Psychology, 23, 587-624.

Johnson, C. M. (2015). The cognitive ecology of dolphin social engagement. In D. L. Herzing \& C. M. Johnson (Eds.), Dolphin communication and cognition (pp. 229-256). Cambridge, MA: MIT Press. 
Johnson, C. M., Karnowski, J., Jacques, D., Lew, Z., Hutchins, E., \& Hildebrand, J. (2015). Signature whistle use by bottlenose dolphins at Brookfield Zoo. $21^{\text {st }}$ Biennial Conference on the Biology of Marine Mammals, December 13-18, San Francisco.

Johnson, C. M., \& Norris, K. S. (1994). Social behavior. In K. S. Norris, B. Würsig, R. S. Wells, \& M. Würsig (Eds.), The Hawaiian spinner dolphin (pp. 243-287). Berkeley, CA: University of California Press.

Johnson, M. P., \& Tyack, P. L. (2003). A digital acoustic recording tag for measuring the response of wild marine mammals to sound. IEEE Journal of Oceanic Engineering, 28, 3-12.

Kaburu, S. S. K., \& Newton-Fisher, N. E. (2013). Social instability raises the stakes during social grooming among wild male chimpanzees. Animal Behaviour, 86, 519-527.

Kaburu, S. S. K., \& Newton-Fisher, N. E. (2015). Trading or coercion? Variation in male mating strategies between two communities of East African chimpanzees. Behavioral Ecology and Sociobiology, 6, 20634.

Keverne, E. B., Martensz, N. D., \& Tuite, B. (1989). Beta-endorphin concentrations in cerebrospinal fluid of monkeys are influenced by grooming relationships. Psychoneuroendocrinology, 14, 155-161.

King, S. L., Sayigh, L. S., Wells, R. S., Fellner, W., \& Janik, V. M. (2013). Vocal copying of individually distinctive signature whistles in bottlenose dolphins. Proceedings of the Royal Society B, 280, 1-9.

Knörnschild, M., Nagy, M., Metz, M., Mayer, F., \& von Helversen, O. (2010). Complex vocal imitation during otogeny in a bat. Biological Letters, 6, 156-159.

Koenig, W. D., \& Dickinson, J. L. (2004). Ecology and evolution of cooperative breeding in birds. Cambridge, MA: Cambridge University Press.

Kuczaj, S. A., \& Yeater, D. B. (2006). Dolphin imitation: Who, what, when and why? Aquatic Mammals, 32, 413422.

Kutsukake, N., \& Clutton-Brock, T. H. (2008). The number of subordinates moderates intrasexual competition among males in cooperatively breeding meerkats. Proceedings of the Royal Society, B, 275, 209-216.

Lakin, J. L., \& Chartrand, T. L. (2003). Using nonconscious behavioral mimicry to create affiliation and rapport. Psychological Science, 14, 334-339.

Leavens, D. A., Russell, J. L., \& Hopkins, W. D. (2005). Intentionality as measured in the persistence and elaboration of communication by chimpanzees (Pan troglodytes). Child Development, 76, 291-306.

Lorberbaum, J. P., Bohning, D. E., Shastri, A., \& Sine, L. E. (2001). Are there really no evolutionarily stable strategies in the iterated Prisoner's Dilemma? Journal of Theoretical Biology, 214, 155-169.

Mann, J., Connor, R., Barre, L., \& Heithaus, M. (2000). Female reproductive success in bottlenose dolphins (Tursiops sp.): Life history, habitat, provisioning, and group size effects. Behavioral Ecology, 11, 210-219.

Marler, P. (1997). Three models of song learning: Evidence from behavior. Journal of Neurobiology, 33, 501-516.

Miyata, Y., \& Norman, D.A. (1986). Psychological issues in support of multiple activities. In D. A. Norman \& S. W. Draper (Eds.) User Centered System Design: New Perspectives on Human-Computer Interaction, (pp. 265-284). Hillsdale, NJ: Lawrence Erlbaum Associates.

Murayama, T., Iijima, S., Katsumata, H., \& Arai, K. (2014). Vocal imitation of human speech, synthetic sounds and beluga sounds, by a beluga (Delphinapterus leucas). International Journal of Comparative Psychology, 27, 369-384.

Nielsen, M., Collier-Baker, E., Davis, J. M., \& Suddendorf, T. (2005). Imitation recognition in a captive chimpanzee (Pan troglodytes). Animal Cognition, 8, 31-36.

Nishida, T. (1983). Alpha status and agonistic alliance in wild chimpanzees (Pan troglodytes schweinfurthii). Primates, 24, 318-336.

Nishida, T., \& Hosaka, K. (1996). Coalition strategies among adult male chimpanzees of the Mahale Mountains, Tanzania. In W. C. McGrew, L. F. Marchant, \& T. Nishida (Eds.), Great ape societies (pp. 114-134). Cambridge, MA, Cambridge University Press.

Noë, R. (2006). Cooperation experiments: Coordination through communication versus acting apart together. Animal Behaviour, 71, 1-18.

Noë, R., \& Hammerstein, P. (1994). Biological markets: Supply and demand determine the effect of partner choice in cooperation, mutualism, and mating. Behavioral Ecology and Sociobiology, 35, 1-11.

Noë, R., van Schaik, C. P., \& van Hooff, J. A. R. A. M. (1991). The market effect: An explanation for pay-off asymmetries among collaborating animals. Ethology, 87, 97-118.

Noë, R., \& Voelkl, B. (2013). Cooperation and biological markets: The power of partner choice. In K. Sterelny, R. Joyce, B. Calcott, \& B. Fraser (Eds.), Cooperation and its evolution (pp. 131-151). Cambridge, MA: MIT Press.

Norris, K. S., \& Dohl, T. (1980). The structure and function of cetacean schools. In L. M. Herman (Ed.), Cetacean behavior: Mechanisms and functions (pp. 211-262). New York: Wiley Interscience. 
Nowacek, D. P (2002) Sequential foraging behaviour of bottlenose dolphins, Tursiops truncatus, in Sarasota Bay, FL. Behaviour, 139, 1125-1145.

Nowak, M. A., \& Sigmund, K. (1998). Evolution of indirect reciprocity by image scoring. Nature, 393, $575-577$.

Pack, A. A. (2015). Experimental studies of dolphin cognitive abilities. In D. L. Herzing \& C. M. Johnson (Eds.), Dolphin communication and cognition (pp. 175-200). Cambridge, MA: MIT Press.

Paukner, A., Anderson, J. R., Borelli, E., Visalberghi, E., \& Ferrari, P. F. (2005). Macaques (Macaca nemestrina) recognize when they are being imitated. Biological Letters, 1, 219-222.

Paukner, A., Suomi, S. J., Visalberghi, E., \& Ferrari, P. F. (2009). Capuchin monkeys display affiliation toward humans who imitate them. Science, 325, 880-883

Payne, K., \& Payne, R. S. (1985). Large scale change over 19 years in songs of humpback whales in Bermuda. Zeit. Tierpsychologie, 68, 89-114.

Perelberg, A., \& Schuster, R. (2009). Bottlenose dolphins (Tursiops truncates) prefer to cooperate when petted: Integrating proximate and ultimate explanations II. Journal of Comparative Psychology, 123, 45-55.

Perry, S., Panger, M., Rose, L. M., Baker, M., Gros-Louis, J., Jack, K., ... \& Pyle, K. (2003). Traditions in whitefaced capuchin monkeys. In D. M. Fragaszy, \& S. Perry (Eds.), The biology of traditions: Models and evidence (pp. 391-425). Cambridge, MA: Cambridge University Press.

Perry, S., Barrett, H. C., \& Manson, J. H. (2004). White-faced capuchin monkeys show triadic awareness in their choice of allies. Animal Behaviour, 67, 165-170.

Petricig, R. O. (1995). Bottlenose dolphins (Tursiops truncatus) in Bull Creek, South Carolina. (Unpublished doctoral dissertation). University of Rhode Island, Kingston, Rhode Island.

Poole, J. H., Tyack, P. L., Stoeger-Horwath, A. S., \& Watwood, S. (2005). Elephants are capable of vocal learning. Nature, 434, 455-456.

Port, M., Clough, D., \& Kappeler, P. M. (2009). Market effects offset the reciprocation of grooming in free-ranging redfronted lemurs, Eulemur fulvus rufus. Animal Behaviour, 77, 29-36.

Ralls, K., Fiorelli, P., \& Gish, S. (1985). Vocalizations and vocal mimicry in captive harbour seals, Phoca vitulina. Canadian Journal of Zoology, 63, 1050-1056.

Rendell, L., \& Whitehead, H. (2001). Culture in whales and dolphins. Behavioral and Brain Sciences, 24, 309-382.

Richards, D. G., Wolz, J. P., \& Herman, L. M. (1984). Vocal mimicry of computer generated sounds and vocal labeling of objects by a bottlenosed dolphin, Tursiops truncatus. Journal of Comparative Psychology, 98, 1028.

Ridgway, S., Carder, D., Jeffries, M., \& Todd, M. (2012). Spontaneous human speech mimicry by a cetacean. Current Biology, 22, R860-R861.

Samuels, A., \& Flaherty, C. (2000). Peaceful conflict resolution in the sea? In F. Aureli, \& F. B. M. de Waal, (Eds.), Natural Conflict Resolution (pp. 229-231). Berkeley, CA: University of California Press.

Sayigh, L. S., Esch, H. C., Wells, R. S., \& Janik, V. M. (2007). Facts about signature whistles of bottlenose dolphins (Tursiops truncatus). Animal Behavior, 74, 1631-1642.

Seyfarth, R. M. (1977). A model of social grooming among adult female monkeys. Journal of Theoretical Biology, 65, 671-698.

Silk, J. B. (1994). Social relationships of male bonnet macaques: male bonding in a matrilineal society. Behaviour, 130,271-291.

Silk, J. B. (1999). Male bonnet macaques use information about third-party rank relationships to recruit allies. Animal Behaviour, 58, 45-51.

Smith, J. E., Memenis, S. K., \& Holekamp, K. E. (2007). Rank-related partner choice in the fission-fusion society of the spotted hyena (Crocuta crocuta). Behavioral Ecology and Sociobiology, 61, 753-765.

Smith, T. G., Siniff, D. B., Reichle, R., \& Stone, S. (1981). Coordinated behavior of killer whales, Orcinus orca, hunting a crabeater seal, Lobodon carcinaphagus. Canadian Journal of Zoology, 59, 1185-1189.

Smuts, B. B. (1985). Sex and friendship in baboons. New York, New York: Aldine.

Smuts, B. B., \& Watanabe, J. M. (1990). Social relationships and ritualized greetings in adult male baboons (Papio cynocephalus Anubis). International Journal of Primatology, 11, 147-172.

Speier, C., Vessey, I. \& Valacich, J. S. (2003). The effects of interruptions, task complexity, and information presentation on computer-supported decision-making performance. Decision Sciences, 34: 771-797.

Spruijt, B. M., van Hooff, J. A. R. A. M., \& Gispen, W. H. (1992). Ethology and neurobiology of grooming behavior. Physiological Reviews, 72, 825-852.

Starkhammar, J., Amundin, M., Nilsson, J., Jansson, T., Almqvist, M., \& Persson, H. W. (2012). Design and benchmark tests of a multi-channel hydrophone array system for dolphin echolocation recordings. Open Journal of Acoustics, 2, 121-130. 
Strum, S. C. (1987). Almost human. Chicago: University of Chicago Press.

Strum, S. C., Forster, D., \& Hutchins, E. (1997). Why Machiavellian intelligence may not be Machiavellian. In A. Whiten \& R.W. Byrne (Eds.), Machiavellian Intelligence II: Extensions and evaluations (pp. 50-85). Cambridge, MA: Cambridge University Press.

Suchak, M., \& de Waal, F. B. M. (2012). Monkeys benefit from reciprocity without the cognitive burden. Proceedings of the National Academy of Sciences, 109, 15191-15196.

Tayler, C. K., \& Saayman G. S. (1973). Imitative behaviour by Indian Ocean bottlenose dolphins (Tursiops aduncus) in captivity. Behaviour, 46, 286-98.

Thomas, R. E., Fristrup, K. M., \& Tyack, P. (2002). Linking the sounds of dolphins to their locations and behavior using video and multichannel acoustic recordings. Journal of the Acoustical Society of America, 112, 16921701.

Thorndike, E. L. $(1898,1911)$. Animal intelligence: An experimental study of the associative processes in animals. Psychological Monographs \#8.

Thornhill, R. (1984). Alternative female choice tactics in the scorpion fly Hylobittacus apicalis (Mecoptera) and their implications. American Zoologist, 24, 367-383.

Tomasello, M., \& Call, J. (1997). Primate cognition. Oxford, UK: Oxford University Press.

Tomasello, M., Gust, D., \& Frost, G. (1989). A longitudinal investigation of gestural communication in young chimpanzees. Primates, 30, 35-50.

Trivers, R. L. (1971). The evolution of reciprocal altruism. Quarterly Review of Biology, 46, 35-57.

Tyack, P. (1986). Whistle repertoires of two bottlenosed dolphins, Tursiops truncatus: Mimicry of signature whistles? Behavioral Ecology and Sociobiology, 18, 251-257.

van Baaren, R. B., Holland, R. W., Kawakami, K., \& van Knippenberg, A. (2004). Mimicry and prosocial behavior. Psychological Science, 15, 71-74.

Visser, I. N., Smith, T. G., Bullock, I. D., Green, G. D., Carlsson, O. G. L., \& Imberti, S. (2007). Antarctic peninsula killer whales (Orcinus orca) hunt seals and a penguin on floating ice. Marine Mammal Science, 24, 225-234.

Watwood, S. L. (2003). Whistle use and whistle sharing by allied male bottlenose dolphins, Tursiops truncatus. (Unpublished doctoral dissertation). Woods Hole Oceanographic Institution, Woods Hole, MA.

Weaver, A. (2003). Conflict and reconciliation in captive bottlenose dolphins, Tursiops truncatus. Marine Mammal Science, 19: 836-846.

Wei, W., Qi, X., Garber, P. A., Guo, S., Zhang, P., \& Li, B. (2016). Supply and demand determine the market value of access to infants in the golden snub-nosed monkey (Rhinopithecus roxellana). PLOS ONE, 8(6), e65962. doi: 10.137/journal.pone.0065962.

Wells, R. S. (2003). Dolphin social complexity: Lessons from long-term study and life history. In F. B. M. de Waal, \& P. L. Tyack (Eds.), Animal social complexity (pp. 32-56). Cambridge, MA: Harvard University Press.

Wells, R. S., Irvine, A. B., \& Scott, M. D. (1980). The social ecology of inshore odontocetes. In L. M. Herman (Ed.), Cetacean behavior (pp. 263-317). New York, NY: Wiley Interscience.

Welsh, L. S., \& D. L. Herzing. (2008). Preferential association among kin exhibited in a population of Atlantic spotted dolphins (Stenella frontalis). International Journal of Comparative Psychology, 21, 1-11.

Würsig, B., \& Würsig, M. (1979). Behavior and ecology of the dusky dolphin, Lagenorhunchus obscurus, in the south Atlantic. Fishery Bulletin, 77, 871-890.

Xitco, M. J., \& Roitblat, H. L. (1996). Object recognition through eavesdropping: Passive echolocation in bottlenose dolphins. Animal Learning \& Behavior, 24, 355-365.

Yamamoto, C., Morisaka, T., Furuta, K., Ishibashi, T., Yoshida, A., Taki, M., Amano, M. (2015). Post-conflict affiliation as conflict management in captive bottlenose dolphins (Tursiops truncatus). Scientific Reports, 5, 14275.

Zacks, J. \& Tversky, B. (2001). Event structure in perception and cognition. Psychological Bulletin, 127: 3-21.

Zahavi, A. (1995). Altruism as a handicap: The limitations of kin selection and reciprocity. Journal of Avian Biology, 26,1-3.

Zlatev, J. (2007). Language, embodiment and mimesis. In T. Ziemke, J. Zlatev, \& R. Frank (Eds.), Body, language, mind (pp. 297-337). Berlin, Germany: de Gruyter. 